\title{
Childhood Obesity Evidence Base Project: Methods for Taxonomy Development for Application in Taxonomic Meta-Analysis
}

\author{
Heather King, PhD,' Mackenzie Magnus, MPH, MBA,' Larry V. Hedges, PhD,' Chris Cyr, BS,' \\ Deborah Young-Hyman, $\mathrm{PhD}^{3}{ }^{2}$ Laura Kettel Khan, $\mathrm{PhD}{ }^{4}$ Lori A.J. Scott-Sheldon, $\mathrm{PhD},{ }^{5,6}$ \\ Jason A. Saul, JD, '7 Sonia Arteaga, PhD, John Cawley, PhD, ${ }^{8,9}$ Christina D. Economos, PhD, ${ }^{10}$ \\ Debra Haire-Joshu, PhD, RN,' ' Christine M. Hunter, PhD, ${ }^{3}$ Bruce Y. Lee, MD, MBA, ${ }^{12}$ \\ Shiriki K. Kumanyika, PhD, MPH, ${ }^{13}$ Lorrene D. Ritchie, PhD, RD, ${ }^{14}$ \\ Thomas N. Robinson, MD, MPH, ${ }^{15}$ and Marlene B. Schwartz, $\mathrm{PhD}^{16}$
}

\section{Abstract}

Meta-analysis has been used to examine the effectiveness of childhood obesity prevention efforts, yet traditional conventional metaanalytic methods restrict the kinds of studies included, and either narrowly define mechanisms and agents of change, or examine the effectiveness of whole interventions as opposed to the specific actions that comprise interventions. Taxonomic meta-analytic methods widen the aperture of what can be included in a meta-analysis data set, allowing for inclusion of many types of interventions and study designs. The National Collaborative on Childhood Obesity Research Childhood Obesity Evidence Base (COEB) project focuses on interventions intended to prevent childhood obesity in children 2-5 years old who have an outcome measure of BMI. The COEB created taxonomies, anchored in the Social Ecological Model, which catalog specific outcomes, intervention components, intended recipients, and contexts of policies, initiatives, and interventions conducted at the individual, interpersonal, organizational, community, and societal level. Taxonomies were created by discovery from the literature itself using grounded theory. This article describes the process used for a novel taxonomic meta-analysis of childhood obesity prevention studies between the years 2010 and 2019. This method can be applied to other areas of research, including obesity prevention in additional populations.

Keywords: intervention; meta-analysis; prevention; taxonomy

\footnotetext{
'Impact Genome Project, Mission Measurement, Chicago, IL, USA.

${ }^{2}$ Department of Statistics, Northwestern University, Evanston, IL, USA.

${ }^{3}$ Office of Behavioral and Social Sciences, Office of the Director, National Institutes of Health, Bethesda, MD, USA.

${ }^{4}$ Division of Nutrition, Physical Activity, and Obesity, Centers for Disease Control and Prevention, Atlanta, GA, USA.

${ }^{5}$ Centers for Behavioral and Preventive Medicine, The Miriam Hospital, Providence, RI, USA.

${ }^{6}$ Department of Psychiatry and Human Behavior, Warren Alpert Medical School of Brown University, Providence, RI, USA.

${ }^{7}$ Office of the Director, National Institutes of Health, Bethesda, MD, USA.

Departments of ${ }^{8}$ Policy Analysis and Management and ${ }^{9}$ Economics, Cornell University, Ithaca, NY, USA.

${ }^{10}$ Friedman School of Nutrition Science and Policy, Tufts University, Boston, MA, USA.

"Center for Obesity Prevention and Policy Research, Brown School Washington University, Saint Louis, MO, USA.

${ }^{12}$ CUNY Graduate School of Public Health and Policy, New York, NY, USA.

${ }^{13}$ Department of Community Health and Prevention, Dornsife School of Public Health, Drexel University, Philadelphia, PA, USA.

${ }^{14}$ Nutrition Policy Institute, University of California Agriculture and Natural Resources, Berkeley, CA, USA.

${ }^{15}$ Stanford Solutions Science Lab, Stanford University, Stanford, CA, USA.

${ }^{16}$ Department of Human Development and Family Studies, University of Connecticut, Hartford, CT, USA.

${ }^{17}$ Center for Impact Sciences, Harris School of Public Policy, University of Chicago, Chicago, IL, USA.
} 


\section{Introduction}

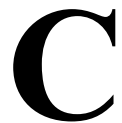
hildhood obesity is a persistent problem in the United States, and significant resources have been devoted to its prevention and treatment. ${ }^{1}$ While there is abundant research on how to prevent childhood obesity, these learnings are not always accessible to practitioners, in part, because they have not been centrally collected and organized. ${ }^{2,3}$ In addition, meta-analyses that aim to uncover effective interventions are traditionally applied to a narrow subset of the available evidence. Here we address both challenges by generating a set of taxonomies that classify available evidence from the childhood obesity prevention literature, and applying taxonomic meta-analysis, an approach that can accommodate a broad range of study design; this method is described in detail in the accompanying Rational article. ${ }^{4}$

The generation and use of taxonomies are not new to efforts to improve public health. Taxonomies, or classification schemes, provide a broad framework intended to promote and integrate evidence into health practices, systems, and policies. For example, a taxonomy for obesity prevention generated by Colquhoun et al. classifies approaches, target beneficiaries, and outcomes. ${ }^{5}$ However, the Colquhoun et al. framework provides a priori definitions for elements of interventions, including active ingredients, causal mechanisms, modes of delivery, and intended targets, but not necessarily the specific components that would be included in each category. This limits the usefulness of the taxonomy in that identifying studies that contain descriptions of, for example, active ingredients only tells the reader that one or more active ingredients were included, but does not tell them what the active ingredients were. Similarly, the work of Michie et al. organizes the sources of behavior, intervention functions, and policy categories relevant in public health into the Behavior Change Wheel. ${ }^{6}$ These frameworks categorize the types of strategies that interventions may use (e.g., "Training" or "Education"), but do not codify discrete specific actions that take place in public health interventions, and thus may be insufficient for either explaining implementation to practitioners or taxonomic metaanalytic uses. For example, the category "training" could contain several specific strategies, such as content-specific training (learning about causes of obesity), pedagogical training, or training on a specific curriculum. Each of these could be further broken down by delivery channel.

The National Childhood Collaborative on Obesity Research's (NCCOR) Childhood Obesity Evidence Base (COEB) project, discussed here, expands on the efforts of Michie, Colquhoun, and others by describing and classifying the components of childhood obesity prevention interventions. Breaking an intervention into specific components is a well-established practice in implementation science, where it allows researchers to examine if, and the extent to which, components occur and how they relate to desired outcomes. ${ }^{7,8}$ In the COEB project, we apply the same principle to childhood obesity prevention interventions and use taxonomic meta-analysis to isolate the discrete activities, which may relate to positive child outcomes in a variety of contexts and populations. This article details the methodology used to generate the taxonomy specific to childhood obesity prevention interventions targeting children ages $2-5$, which can be applied to other areas of research, including obesity prevention for other populations. The taxonomy described here is also the foundation for a taxonomic meta-analysis, described in the accompanying Results article. ${ }^{9}$

\section{Methods}

To execute taxonomic meta-analysis, the first task was to create taxonomies that catalog the outcomes, intervention components (hereby referred to as "components"), intended recipients, and contexts of policies and interventions intended to prevent obesity in children aged 2-5 years, as described in studies that included an outcome of measured BMI. Unlike fields in which interventions are primarily individually or clinically focused, interventions to prevent childhood obesity are often population focused and classified as policy, system, or environmental prevention strategies. The COEB NCCOR workgroup (WG) and its External Expert Panel (EEP) recommended using the social ecological model to anchor the COEB taxonomic development. ${ }^{10}$ This framework is well-accepted in the field of obesity prevention and includes five nested levels at which interventions may act: individual, interpersonal, organizational, community, and societal. ${ }^{11}$

The second task was to apply these taxonomies to a set of childhood obesity studies (51 unique studies with 147 supplemental documents) following the PRISMA checklist described in the accompanying Results article. ${ }^{9}$ For the purposes of the COEB project, the word "studies" is the number of research studies included in the taxonomic meta-analysis. This is inclusive of all reported elements of an intervention, their codes, and their effects. The application of the taxonomies to this literature, along with characteristics of research or implementation design and measures of effect, produces a searchable database of coded studies and a data set for taxonomic meta-analysis. This database can be modified with the addition of evidence from new reports and is available for future analysis online at: https://www.nccor.org/ childhood-obesity-evidence-base-test-of-a-novel-taxonomicmeta-analytic-method

The third task was to use taxonomic meta-analysis to investigate the relationship of intervention components and effect size with consideration for contextual differences, allowing the identification of which intervention components correlate most with childhood obesity prevention for the intended recipients. (See accompanying Rationale article for a description of taxonomic metaanalysis. $)^{4}$ A complete description of the taxonomies in relation to the social ecological model, the database of 
coded studies, and other project materials are available online (see above link).

\section{Taxonomy Development}

Taxonomies were developed to describe elements of childhood obesity interventions, including intended recipients, implementation process, contextual elements, and the desired outcomes. Just as effect sizes can be standardized and compared across interventions, these facets of interventions can also be standardized, allowing for a clear understanding of what is being done, with whom, by whom, where, and for what purpose. To standardize constructs across interventions with diverse topics, goals, and settings, COEB taxonomy development used a component approach in which interventions were examined at the level of their essential activities. This is a novel application of the component approach, but an idea that has been suggested by others. ${ }^{12-14}$

For the COEB project, a consistent methodology was used to create four distinct taxonomies that together describe a given childhood obesity prevention intervention or policy:

- Outcomes that interventions or policies were aiming to achieve.

- Intervention components ("components") that interventions or policies used to achieve one or more outcomes.

- Intended recipients that interventions or policies served (children ages 2-5).

- Intervention contexts relevant to how interventions or policies were delivered, including, but not limited to, location, setting, and facilitator characteristics.

Taxonomies were created by discovering components from the childhood obesity prevention literature using the qualitative research technique grounded theory. ${ }^{15,16}$ Through this approach, coding categories arise from line by line examination of text in a "training" set of studies. This training set was selected to represent the breadth of the entire corpus of studies by identifying articles that were diverse in design, population, and context. Seventy-three percent of the articles in the training set met the necessary criteria for inclusion in the taxonomic meta-analysis data set. ${ }^{9}$

The codes that emerged from the training set of studies were then grouped conceptually and condensed by linking coded items that have comparable meaning. As new concepts were encountered, new codes were created until a point of saturation when new concepts were no longer discovered. The organized codes that emerged from this process constituted the draft taxonomies. The process identified concepts in the language of the study, and organized and standardized the concepts, rather than imposing a theoretical framework or perspective or placing value on the activities. Establishment of a robust set of taxonomies generally requires a training set of at least 40 articles; the first 15 articles tend to yield roughly $70 \%$ of the taxonomy components and the next 25 articles yield the remainder. This is consistent with Tran et al., ${ }^{17}$ who examined the number of sources needed to reach saturation when extracting themes from open-ended survey responses. The authors used Monte Carlo simulations to determine that at least 50 sources would be needed to accurately predict the number of themes within a qualitative data set. While the training set contained 40 articles, the resulting taxonomy was applied to the full data set of 58 intervention descriptions, and only 3 additional codes (compared with 90 codes identified using the training set) were found through that process. In addition, the NCCOR WG and EEP suggested codes not found in the training set that they anticipated might be present in the full data set of 58 intervention descriptions.

The training set for COEB was created by bibliographers identifying articles and logging 246 intervention and policy evaluations (Fig. 1) meeting preset selection criteria:

1. Evaluated an intervention or policy.

2. Made a comparison between a recipient and comparison group.

3. Contained sufficient detail about the intervention's components.

4. Measured at least one weight-specific outcome (e.g., BMI, growth trajectory, weight) in children aged $2-5$ years

The article log included peer-reviewed articles and reports authored or recommended by the NCCOR WG, the EEP, and other known experts, as well as from key word searches, research center publication lists, and reference lists of other studies. To construct the draft taxonomies, the research team extracted a stratified random sample from the 246 articles to ensure representation of interventions and policies. The stratification was based on topic areas identified by the EEP, which included interventions focused on sleep behavior, healthy eating, physical activity, screen time reduction, and others. (See online chart of components https:/www.nccor.org/ childhood-obesity-evidence-base-test-of-a-novel-taxonomicmeta-analytic-method) The NCCOR WG and EEP reviewed the training set (40 articles) to ensure that a breadth of childhood obesity prevention efforts were represented.

The articles were divided between the research team (eight individuals) and coded independently using the grounded theory approach (creating codes rather than applying preset codes). Additional information, such as study design and specific measures reported, was also captured. The purpose of this initial coding was to surface information about the range of activities used in childhood obesity prevention interventions or policies. The research team erred on the side of being inclusive to ensure that all distinctive elements discussed in the articles were captured. This process resulted in 1304 coded elements.

During taxonomy development, the research team engaged in discussion throughout the coding process to resolve issues or questions as they emerged. Ten sources 


\section{Search Strategies Employed for Identification}

\begin{tabular}{|c|c|}
\hline $\begin{array}{c}\text { Category 1: articles authored } \\
\text { by members of the COEB } \\
\text { Working Group and External } \\
\text { Expert Panel } \\
1,174 \text { search hits, } \\
\mathbf{6 9} \text { potential records }\end{array}$ & $\begin{array}{l}\text { Category 2: articles authored } \\
\text { by other known childhood } \\
\text { obesity experts } \\
52 \text { potential records }\end{array}$ \\
\hline \multirow[t]{2}{*}{$\begin{array}{l}\text { Category } 4 \text { : articles from } \\
\text { research centers, foundations, } \\
\text { think tanks, and similar } \\
\text { organizations that produce } \\
\text { relevant evaluation research } \\
1,206 \text { search hits, } \\
\mathbf{1 7} \text { potential records }\end{array}$} & $\begin{array}{l}\text { Category 5: articles from } \\
\text { reference lists of meta- } \\
\text { analyses, reviews, and book } \\
\text { chapters } \\
63 \text { potential records }\end{array}$ \\
\hline & 11 duplicates removed \\
\hline Identification & $\begin{array}{c}356 \\
\text { potential records for taxonomy } \\
\text { development }\end{array}$ \\
\hline $\begin{array}{l}\text { Screening / } \\
\text { Eligibility }\end{array}$ & $\begin{array}{c}246 \\
\text { records meeting criteria based on } \\
\text { abstract }\end{array}$ \\
\hline Inclusion & $\begin{array}{l}\mathbf{4 0} \\
\text { records were selected via } \\
\text { stratified random sampling for } \\
\text { taxonomy development }\end{array}$ \\
\hline
\end{tabular}

Figure 1. Childhood Obesity Evidence Base project taxonomy development article search and selection process. This compilation was not intended to be comprehensive but representative of the prevention efforts within the topic scoping. For searches that returned over 100 results, only the first 100 were reviewed.

(25\%) were coded by two or more individuals. Double coding was conducted primarily to ensure consistency in the level of detail of codes, and conceptual agreement. The researchers had to all agree on the final set of codes based on discussions of the double coding. Given that this was part of the taxonomy derivation process, as opposed to the taxonomy application process, inter-rater reliability metrics, such as Cohen's kappa, were not appropriate. The coded text was then organized into components, and the components were organized into conceptual categories.
The lists of categories and more granular components make up the taxonomies. The taxonomies were reviewed and approved by the NCCOR WG and the EEP, as well as compared with existing theory for population-based obesity prevention. Furthermore, the taxonomies were aligned to the social ecological model. This alignment was determined by who was the target of that component. For example, an intervention that includes workshops for parents would be "interpersonal," even if it is implied that an organization would need to run the workshops. 


\section{Outcomes}

Taxonomy development is driven by conceptually standardized outcomes. The impact of childhood obesity prevention interventions can be measured in a variety of standardized ways (measures of weight status or change, food intake, physical activity, screen time, etc.). Outcomes can be clustered to include those that are similarly defined. For example, measures of weight, growth trajectory (specifically changes in weight), and BMI can all be collapsed into "weight status." Thus, once outcomes are defined, they, like components, can be compared across studies. Identifying specific outcomes allows researchers to examine which components may be more effective for that specific outcome, and how the effectiveness may vary depending on context, including characteristics of the intended recipients. For example, effective strategies for increasing the physical activity may be different from effective strategies for changing patterns of food intake, depending on how and where they are implemented, and in what age group.

In the COEB taxonomy, the four outcomes (Table 1) were defined as a measurable change in the intended recipients (children) that a childhood obesity prevention intervention or policy is aiming to achieve. Each of these outcomes may have various forms of measurement. For example, the outcome "weight status" was coded if an article reported child BMI, child BMI z-score, child BMI percentile, and child waist circumference. The outcome "diet" was coded if the article reported dietary intake, fruit/vegetable consumption, sugar-sweetened beverage consumption, fast food consumption, and so on. These four outcomes were drafted after an initial scan of the literature and approved by the NCCOR WG and EEP. However, given the nature of the COEB project, the EEP decided to restrict taxonomy development (components, intended recipients, and context) and the taxonomic meta-analysis to one outcome: weight status. Thus, the training set was restricted to articles that reported at least one measure of BMI, but may have also reported other outcomes (diet, physical activity, and/or sleep). The project final data set used for taxonomic meta-analysis was restricted to measures of BMI. ${ }^{9}$

\section{Intervention Components}

The purpose of the component taxonomy is to capture the specific activities performed by those participating in the intervention, characteristics of the intervention (e.g., "utilize research-based approaches or curriculum" or "used culturally tailored intervention"), policies implemented, instructional strategies, delivery mechanisms, the person or people who delivered the intervention, and topic or content areas. While these elements are separated for classification purposes, they are intended to be recombined in various ways to fully represent a given intervention.

Similar to the other taxonomies, the research team reviewed the coded elements pertaining to the intervention itself, grouped them conceptually, and condensed them into common standardized components that fit under broader categories. For instance, the codes "limit high-fat meats," "remove French fries from children's menu," and "strategies to decrease consumption of sweetened beverages" were grouped together (along with other qualitatively related codes) under one standardized component called "decrease less healthy food options." Then to create categories, components were grouped conceptually. For example, the component "decrease less healthy food options" was grouped with others, including "include opportunities for children to try new foods," "engage child care providers in facilitating healthy eating patterns," and

\begin{tabular}{|c|c|c|}
\hline Individual outcomes & Definitions & Examples \\
\hline Weight status & Attained healthy or recommended weight/BMI & Change in height/weight/BMI (kg/m², percentage, z-scores). \\
\hline Physical activity & $\begin{array}{l}\text { Demonstrated positive changes in physical activity } \\
\text { and/or maintained healthy physical activity }\end{array}$ & Change in physical activity frequency, intensity, or duration. \\
\hline Diet & $\begin{array}{l}\text { Demonstrated positive changes in food intake } \\
\text { and/or maintained healthy diet }\end{array}$ & $\begin{array}{l}\text { Change in vegetable/fruit consumption } \\
\text { Change in sugar-sweetened beverage consumption } \\
\text { Consuming recommended amounts of carbohydrates, protein, } \\
\text { and fat }\end{array}$ \\
\hline Sleep & $\begin{array}{l}\text { Demonstrated positive changes in sleep behavior } \\
\text { and/or maintained healthy sleep behavior }\end{array}$ & $\begin{array}{l}\text { Change in sleep hygiene/sleep quantity and/or quality } \\
\text { Change in bedtime routine }\end{array}$ \\
\hline
\end{tabular}

The outcomes' taxonomy categorizes common child-level individual outcomes. Given the nature of this project, taxonomic meta-analysis of the final $5 \mathrm{I}$ studies was restricted to those with multiple measures of BMI. 
"provide healthy recipes/shopping lists/menus to caregivers" to make up the component category "activities related to food/food environment."

Some coded text segments were not condensed under a component, as they were either too general, too esoteric, or not frequent enough to warrant their own component. For example, the coded text segments "provide child-focused materials" and "provided innovative activities for children" were grouped under the "instructional strategies" category but were not specific enough to be added to a component. Coded text segments such as "used chopsticks as tool," and "used child drinking cup as a tool" were very specific to a single intervention and were not grouped under a component. In addition, some coded text segments were not condensed into a component because there were too few of them relative to the number of coded text segments under other components. An example would be the coded text "deliver sessions in talk show format." If there were other coded text segments that were conceptually similar, there would have been a component related to talk show formats under the category of "instructional strategies." Since this was only found once in the training set of 40 articles, this component was not added to the components' taxonomy. This was assessed case-by-case, but generally components were not created unless there were five or more instances found in the 40 articles. It may be surprising to find that certain activities were not frequently found in the training set, but this highlights the utility of taxonomies applied to research articles. There are no standards for which aspects of interventions are described, and authors may leave out details at their discretion, especially if those details are seen as common or ubiquitous.

As the components were grouped in their appropriate categories, it was apparent that there were some components missing that we anticipated seeing based on the field. For instance, "engage facilitators in praise/encouragement for positive health-related behavior" was added to mirror "engage caregivers in praise/encouragement for positive health-related behavior." Similarly, "decrease less healthy food options" was added to mirror "increase healthy food options" and "provide nutrition education and training to facilitators" to mirror the caregiver counterpart. Lastly, the WG and EEP recognized the importance of understanding who was engaged in the intervention development. Thus, the following components were added: "engage caregiver/family in intervention development," "engage child care providers in intervention development," and "engage pediatricians/health care providers in intervention development."

As mentioned previously, the majority of components are identified through the training set of 40 articles, but grounded theory allows for the addition of components if they emerge in subsequent articles. As the coding was expanded to a separate comprehensive study search (described in more detail below), the taxonomies continued to evolve, although gradually, as few components emerged that were not already well-described by the initial components' taxonomy. For instance, one language adjustment and six new components were added. The adjustment was the addition of "menus" to the components "provide healthy recipes/shopping lists to caregivers." The six additions included were as follows: "engage facilitators in praise/encouragement for positive health-related behavior," "utilize field trips/site visits," "provide materials to support self-control in children," "implement support groups for caregivers," "include free play," and "engage caregivers in facilitating healthy eating patterns."

The 93 components and 9 component categories that emerged as part of the components' taxonomy are summarized in Table 2 and further defined in the online supporting material. Each category subsumes as few as 5 to as many as 23 specific components. For example, the category "activities related to food/food environment" includes 10 components (e.g., "provide healthy recipes/ shopping lists/menus to caregivers," "decrease less healthy food options").

\section{Intended Recipients and Intervention Context}

The intended recipient taxonomy captures characteristics of the population in which the intervention outcomes were measured - for the COEB project, children ages 2-5. All other contexts are captured in the intervention context taxonomy, including information about the intervention setting, facilitators, community in which the intervention took place, and other intervention participants (e.g., parents and family members participating in the intervention). Sample components for the intended recipients and intervention context taxonomies are listed in Tables 3 and 4, respectively.

Like components, each intended recipient category subsumes as few as 1 to as many as 20 specific components. For example, the category "weight status" includes components such as "overweight," "obese," "normal weight," "underweight," "at risk for obesity." Each intervention context category subsumes as few as 2 to as many as 15 specific components. For example, the category "intervention setting" includes codes such as "home based," "early head start/head start programs," and "primary care based." The intended recipient and intervention context components and categories that emerged are given in Tables 2 and 3, respectively, and further details are available in the database online.

\section{The COEB Database}

Once the taxonomies were constructed from the training set of 40 articles, a separate comprehensive study search was conducted and the taxonomies were applied to a total of 51 unique studies and 147 supplemental documents (total of 198 articles) to produce a data set for the 
Table 2. Childhood Obesity Evidence Base Project Intervention Components Identified across the 40 Reports Used for Taxonomy Development

\begin{tabular}{|c|c|c|c|c|c|c|}
\hline \multirow[b]{2}{*}{ Intervention components } & \multicolumn{5}{|c|}{ Socioecological model ${ }^{a}$} & \multirow[b]{2}{*}{ Frequency, $\%$} \\
\hline & Individual & Interpersonal & Organizational & Community & Societal & \\
\hline \multicolumn{7}{|l|}{ Activities to support behavior change } \\
\hline Implement structures of accountability & $x$ & $x$ & $x$ & & l & 38 \\
\hline $\begin{array}{l}\text { Incorporate implementation } \\
\text { of self-reflection strategies }^{c}\end{array}$ & l & $x$ & $x$ & & & \\
\hline Implement media campaigns & & $x$ & I & l & 1 & 8 \\
\hline Incorporate financial incentives & & $x$ & $x$ & & & 40 \\
\hline $\begin{array}{l}\text { Engage facilitators in praise/ } \\
\text { encouragement for health-related } \\
\text { behavior }^{c}\end{array}$ & & $x$ & $x$ & & & \\
\hline $\begin{array}{l}\text { Engage caregivers in praise/ } \\
\text { encouragement for positive } \\
\text { health-related behavior }\end{array}$ & & $x$ & $x$ & & & 15 \\
\hline Engage caregivers in goal setting & & $x$ & & & & 25 \\
\hline $\begin{array}{l}\text { Engage caregivers to serve as role } \\
\text { models for children }\end{array}$ & l & $x$ & $x$ & & & 8 \\
\hline \multicolumn{7}{|l|}{ Instructional strategies } \\
\hline $\begin{array}{l}\text { Provide toys/books/games/stickers } \\
\text { for child engagement }\end{array}$ & $x$ & 1 & & & & 28 \\
\hline Utilize arts and music & $x$ & $x$ & $x$ & & & 15 \\
\hline $\begin{array}{l}\text { Utilize games, imaginative play, } \\
\text { or storytelling }\end{array}$ & $x$ & $x$ & $x$ & & & 23 \\
\hline Utilize a stepped-intensity approach & & $x$ & $x$ & & & 8 \\
\hline Utilize written activities & l & $x$ & $x$ & & & 3 \\
\hline Utilize modeling/demonstration & & $x$ & $x$ & & & 13 \\
\hline Utilize media for instruction & $x$ & $x$ & & & & 20 \\
\hline Utilize hands-on approach & $x$ & $x$ & & & & 10 \\
\hline Utilize reflective listening & & $x$ & $x$ & & & 5 \\
\hline Utilize discussion & & $x$ & $x$ & & & 8 \\
\hline Utilize role-playing for instruction & & $x$ & & & & 8 \\
\hline Utilize group instruction & $x$ & $x$ & & & & 28 \\
\hline Utilize telephone calls & & $x$ & $x$ & & & 15 \\
\hline $\begin{array}{l}\text { Utilize dual language } \\
\text { instruction/materials }\end{array}$ & & $x$ & $x$ & & & 30 \\
\hline Utilize field trips/site visits ${ }^{c}$ & l & $x$ & $x$ & & & \\
\hline \multicolumn{7}{|l|}{ Activities for supporting caregivers } \\
\hline $\begin{array}{l}\text { Engage experts to provide technical } \\
\text { assistance to caregivers }\end{array}$ & & $x$ & $x$ & & & 10 \\
\hline $\begin{array}{l}\text { Provide audiovisual media resources } \\
\text { to caregivers }\end{array}$ & & $x$ & $x$ & & & 8 \\
\hline $\begin{array}{l}\text { Provide materials to support healthy } \\
\text { eating patterns to caregivers }\end{array}$ & & $x$ & $x$ & & & 25 \\
\hline $\begin{array}{l}\text { Provide materials to support screen } \\
\text { time reduction to caregivers }\end{array}$ & & $x$ & $x$ & & & 5 \\
\hline $\begin{array}{l}\text { Provide materials to support } \\
\text { self-control in children }{ }^{c}\end{array}$ & & 1 & I & & & \\
\hline
\end{tabular}


Table 2. Childhood Obesity Evidence Base Project Intervention Components Identified across the $\mathbf{4 0}$ Reports Used for Taxonomy Development continued

\begin{tabular}{|c|c|c|c|c|c|c|}
\hline \multirow[b]{2}{*}{ Intervention components } & \multicolumn{5}{|c|}{ Socioecological model ${ }^{a}$} & \multirow[b]{2}{*}{ Frequency, $\%$} \\
\hline & Individual & Interpersonal & Organizational & Community & Societal & \\
\hline $\begin{array}{l}\text { Provide written resources } \\
\text { to caregivers }\end{array}$ & & $x$ & $x$ & & & 55 \\
\hline $\begin{array}{l}\text { Provide access to social media } \\
\text { platforms/websites to caregivers }\end{array}$ & & $x$ & $x$ & & & 3 \\
\hline $\begin{array}{l}\text { Provide education about obesity } \\
\text { risk/awareness to caregivers }\end{array}$ & & $x$ & $x$ & & & 15 \\
\hline $\begin{array}{l}\text { Provide education about physical } \\
\text { activity to caregivers }\end{array}$ & & $x$ & $x$ & & & 23 \\
\hline $\begin{array}{l}\text { Provide education about healthy } \\
\text { sleep patterns to caregivers }\end{array}$ & & $x$ & $x$ & & & 3 \\
\hline $\begin{array}{l}\text { Provide education about the } \\
\text { importance of routines to caregivers }\end{array}$ & & $x$ & $x$ & & & 3 \\
\hline $\begin{array}{l}\text { Provide education about nutrition } \\
\text { and healthy eating patterns } \\
\text { to caregivers }\end{array}$ & & $x$ & $x$ & & & 15 \\
\hline $\begin{array}{l}\text { Provide education about child } \\
\text { behavior management to caregivers }\end{array}$ & & $x$ & $x$ & & & 25 \\
\hline $\begin{array}{l}\text { Provide education about modeling } \\
\text { healthy behaviors to caregivers }\end{array}$ & & $x$ & $x$ & & & 15 \\
\hline $\begin{array}{l}\text { Provide education about sources } \\
\text { of stress and coping strategies } \\
\text { to caregivers }\end{array}$ & & $x$ & $x$ & & & 5 \\
\hline $\begin{array}{l}\text { Provide education about social and } \\
\text { emotional skills to caregiver }\end{array}$ & & $x$ & $x$ & & & 28 \\
\hline $\begin{array}{l}\text { Provide education about the } \\
\text { importance of built environment } \\
\text { to caregivers }\end{array}$ & & $x$ & $x$ & & & 2 \\
\hline $\begin{array}{l}\text { Provide education about health } \\
\text { and wellness content to caregivers }\end{array}$ & & $x$ & $x$ & & & 4 \\
\hline $\begin{array}{l}\text { Provide education about the } \\
\text { importance of screen time } \\
\text { education to caregivers }\end{array}$ & & $x$ & $x$ & & & I \\
\hline $\begin{array}{l}\text { Include activities to promote } \\
\text { problem-solving to caregivers }\end{array}$ & & $x$ & $x$ & & & 30 \\
\hline $\begin{array}{l}\text { Implement personalized support } \\
\text { for caregivers }\end{array}$ & & $x$ & $x$ & & & 18 \\
\hline $\begin{array}{l}\text { Implement follow-up support } \\
\text { for caregivers }\end{array}$ & & $x$ & $x$ & & & 48 \\
\hline $\begin{array}{l}\text { Implement support groups } \\
\text { for caregiversc }\end{array}$ & & l & l & & & \\
\hline \multicolumn{7}{|l|}{ Facilitator training activities } \\
\hline Use a train, the trainer model & & $x$ & l & & & 8 \\
\hline $\begin{array}{l}\text { Provide curriculum materials } \\
\text { to facilitators }\end{array}$ & & $x$ & $x$ & & & 18 \\
\hline $\begin{array}{l}\text { Provide regular training } \\
\text { opportunities for facilitators }\end{array}$ & & $x$ & $x$ & & & 10 \\
\hline $\begin{array}{l}\text { Provide initial or one-time training } \\
\text { opportunities for facilitators }\end{array}$ & & $x$ & $x$ & & & 13 \\
\hline
\end{tabular}


Table 2. Childhood Obesity Evidence Base Project Intervention Components Identified across the $\mathbf{4 0}$ Reports Used for Taxonomy Development continued

\begin{tabular}{|c|c|c|c|c|c|c|}
\hline \multirow[b]{2}{*}{ Intervention components } & \multicolumn{5}{|c|}{ Socioecological model ${ }^{a}$} & \multirow[b]{2}{*}{ Frequency, ${ }^{\mathrm{b}} \%$} \\
\hline & Individual & Interpersonal & Organizational & Community & Societal & \\
\hline $\begin{array}{l}\text { Provide physical activity education } \\
\text { and training to facilitators }\end{array}$ & & $x$ & $x$ & & & 3 \\
\hline $\begin{array}{l}\text { Provide healthy eating education } \\
\text { and training to facilitators }\end{array}$ & & $x$ & $x$ & & & 10 \\
\hline $\begin{array}{l}\text { Provide food preparation education } \\
\text { and training to facilitators }\end{array}$ & & $x$ & $x$ & & & 3 \\
\hline $\begin{array}{l}\text { Provide nutrition education } \\
\text { and training to facilitators }{ }^{c}\end{array}$ & & l & l & & & \\
\hline \multicolumn{7}{|l|}{ Involvement of facilitators } \\
\hline $\begin{array}{l}\text { Delivered by pediatricians/health } \\
\text { care providers }\end{array}$ & & $x$ & $x$ & & & 15 \\
\hline Delivered by child care providers & & $x$ & $x$ & & & 18 \\
\hline Delivered by families & & $x$ & $x$ & & & 38 \\
\hline $\begin{array}{l}\text { Delivered by community } \\
\text { organizations }\end{array}$ & & 1 & $x$ & $x$ & & 25 \\
\hline \multicolumn{7}{|l|}{ Policy-based strategies } \\
\hline Implement nutrition standards & & & $x$ & I & $x$ & 8 \\
\hline Implement earned income tax credit & & & & & $x$ & 3 \\
\hline Implement SNAP/WIC policies & & & $x$ & & $x$ & 3 \\
\hline $\begin{array}{l}\text { Implement policies regulating food/ } \\
\text { beverage costs }\end{array}$ & & & & I & $x$ & 3 \\
\hline $\begin{array}{l}\text { Implement policies for regulation of } \\
\text { food/beverage access }\end{array}$ & & & $x$ & & $x$ & 8 \\
\hline $\begin{array}{l}\text { Implement policies for increasing } \\
\text { physical activity }\end{array}$ & & & $x$ & l & $x$ & 10 \\
\hline \multicolumn{7}{|l|}{$\begin{array}{l}\text { Activities related to physical activity/ } \\
\text { environment }\end{array}$} \\
\hline Focus on physical activity education & $x$ & $x$ & & & I & 70 \\
\hline $\begin{array}{l}\text { Focus on importance of reduced } \\
\text { screen time }\end{array}$ & $x$ & $x$ & $x$ & & & 45 \\
\hline $\begin{array}{l}\text { Provide materials/Space to support } \\
\text { physical activity to caregivers }\end{array}$ & & $x$ & $x$ & & & 10 \\
\hline $\begin{array}{l}\text { Provide materials/space to support } \\
\text { physical activity to facilitators }\end{array}$ & & $x$ & $x$ & & & 13 \\
\hline $\begin{array}{l}\text { Engage caregivers in supporting } \\
\text { physical activities }\end{array}$ & & $x$ & $x$ & & & 13 \\
\hline $\begin{array}{l}\text { Engage child care providers in sup- } \\
\text { porting physical activity }\end{array}$ & & $x$ & $x$ & & & 8 \\
\hline $\begin{array}{l}\text { Implement reduction of sedentary } \\
\text { behaviors }\end{array}$ & & $x$ & $x$ & & & 5 \\
\hline $\begin{array}{l}\text { Implement "fun" physical activities to } \\
\text { engage children }\end{array}$ & $x$ & $x$ & $x$ & & & 25 \\
\hline Include structured physical activities & $x$ & $x$ & $x$ & & & 18 \\
\hline Include free playc & l & 1 & & & & \\
\hline
\end{tabular}




\section{Table 2. Childhood Obesity Evidence Base Project Intervention Components Identified across the 40 Reports Used for Taxonomy Development continued}

\begin{tabular}{|c|c|c|c|c|c|c|}
\hline \multirow[b]{2}{*}{ Intervention components } & \multicolumn{5}{|c|}{ Socioecological model ${ }^{a}$} & \multirow[b]{2}{*}{ Frequency, ${ }^{\mathrm{b}} \%$} \\
\hline & Individual & Interpersonal & Organizational & Community & Societal & \\
\hline \multicolumn{7}{|l|}{$\begin{array}{l}\text { Activities related to food/food } \\
\text { environment }\end{array}$} \\
\hline Focus on food preparation education & $x$ & $x$ & & & & 20 \\
\hline Focus on nutrition-related education & $x$ & $x$ & $x$ & & & 78 \\
\hline $\begin{array}{l}\text { Provide food to encourage healthy } \\
\text { eating for children }\end{array}$ & $x$ & $x$ & $x$ & & & 8 \\
\hline $\begin{array}{l}\text { Provide healthy recipes/shopping } \\
\text { lists/menus to caregivers }\end{array}$ & & $x$ & $x$ & & & 15 \\
\hline $\begin{array}{l}\text { Engage child care providers } \\
\text { in facilitating healthy eating patterns }\end{array}$ & & $x$ & $x$ & & & 3 \\
\hline $\begin{array}{l}\text { Engage caregivers in facilitating } \\
\text { healthy eating patterns }\end{array}$ & & $x$ & & & & 25 \\
\hline Decrease less healthy food options ${ }^{c}$ & & 1 & I & l & & \\
\hline Increase healthy food options & $x$ & $x$ & $x$ & & & 10 \\
\hline $\begin{array}{l}\text { Include opportunities for children to } \\
\text { prepare foods }\end{array}$ & $x$ & l & $x$ & & & 3 \\
\hline $\begin{array}{l}\text { Include opportunities for children to } \\
\text { try new foods }\end{array}$ & $x$ & $x$ & $x$ & I & & 13 \\
\hline \multicolumn{7}{|l|}{ Characteristics of the intervention } \\
\hline $\begin{array}{l}\text { Utilized recognized standards or } \\
\text { recommendations } s^{c}\end{array}$ & & & $x$ & l & $x$ & \\
\hline $\begin{array}{l}\text { Utilized research-based approaches } \\
\text { or curriculum c }\end{array}$ & & $x$ & $x$ & & & \\
\hline $\begin{array}{l}\text { Documentation of intervention } \\
\text { implementation/quality }\end{array}$ & & $x$ & $x$ & l & l & 20 \\
\hline $\begin{array}{l}\text { Engage caregiver/family } \\
\text { in intervention development }{ }^{c}\end{array}$ & & l & l & & & \\
\hline $\begin{array}{l}\text { Engage child care providers } \\
\text { in intervention development }{ }^{\mathrm{c}}\end{array}$ & & l & l & & & \\
\hline $\begin{array}{l}\text { Engage pediatricians/health } \\
\text { care providers in intervention } \\
\text { development }^{c}\end{array}$ & & l & l & & & \\
\hline Used culturally tailored intervention & $x$ & $x$ & $x$ & $x$ & I & 40 \\
\hline Implement home visits & & $x$ & $x$ & & & 8 \\
\hline Utilize a multilevel approach & $x$ & $x$ & $x$ & $x$ & l & 18 \\
\hline
\end{tabular}

${ }^{a}$ An $\mathrm{X}$ indicates that the socioecological model category was present within the initial 40 studies coded for taxonomy development, a / indicates where the research team, NCCOR Workgroup and External Expert Panel, anticipated finding articles in the expanded bibliography that describes the intervention component at that SEM level.

${ }^{b}$ The overall frequency is the percentage of the 40 reports in the training data set that included the specific component. Frequency of intervention components in the final $5 \mathrm{I}$ studies included in the taxonomic meta-analysis is available online at: https://www.nccor.org/childhoodobesity-evidence-base-test-of-a-novel-taxonomic-meta-analytic-method

'These intervention components were identified after the training set of 40 articles were coded, thus will only be represented in the final database of $5 \mathrm{I}$ coded studies.

NCCOR, National Childhood Collaborative on Obesity Research; SEM, socioecological model; SNAP/WIC, Supplemental Nutrition Assistance Program/Special Supplemental Nutrition Program for Women, Infants, and Children. 
Table 3. Childhood Obesity Evidence Base Project-Intended Recipient Components Identified across the $\mathbf{4 0}$ Reports Used for Taxonomy Development

\begin{tabular}{|c|c|c|c|c|c|c|}
\hline \multirow{2}{*}{$\begin{array}{l}\text { Intended recipient } \\
\text { (children) } \\
\text { characteristics }\end{array}$} & \multirow[b]{2}{*}{ Definition } & \multicolumn{5}{|c|}{ Socioecological model ${ }^{a}$} \\
\hline & & Individual & Interpersonal & Organizational & Community & Societal \\
\hline Level of education & $\begin{array}{l}\text { Reported level of education for } \\
\text { children }\end{array}$ & $\mathrm{x}$ & & & & \\
\hline Age group & $\begin{array}{l}\text { Reported age group of child } \\
\text { participants }\end{array}$ & $x$ & & & & \\
\hline Living arrangements & $\begin{array}{l}\text { Family structure (i.e., living with } \\
\text { both parents, living with one parent, } \\
\text { living with grandparents) }\end{array}$ & $x$ & & & & \\
\hline Gender & Gender of child & $\mathrm{X}$ & & & & \\
\hline $\begin{array}{l}\text { Language spoken } \\
\text { at home }\end{array}$ & $\begin{array}{l}\text { Information about language } \\
\text { spoken and/or language proficiency } \\
\text { (i.e., ELL status) }\end{array}$ & $x$ & & & & \\
\hline $\begin{array}{l}\text { Physical/learning } \\
\text { differences }\end{array}$ & $\begin{array}{l}\text { Learning, behavioral, mental, or } \\
\text { physical differences }\end{array}$ & $x$ & & & & \\
\hline Race/ethnicity & Race or ethnicity of child & $x$ & & & & \\
\hline Socioeconomic status & Socioeconomic status of child & $x$ & & & & \\
\hline Technology access & $\begin{array}{l}\text { Extent to which child has access } \\
\text { to technology in the home }\end{array}$ & $x$ & & & & \\
\hline Health status & $\begin{array}{l}\text { BMI, at risk for obesity, physical } \\
\text { activity level, and so on }\end{array}$ & $x$ & & & & \\
\hline
\end{tabular}

Frequencies are not provided here given the number of characteristics, frequency of characteristics in the final $5 \mathrm{I}$ studies can be found in the accompanying data set online.

${ }^{a} \mathrm{An} \mathrm{X}$ indicates that the socioecological model category was present within the initial 40 studies coded for taxonomy development.

ELL, English language learner.

taxonomic meta-analysis and serve as a "testing" platform for the taxonomies themselves. ${ }^{9}$ The PRISMA flow diagram in the accompanying Results article describes the final set of 51 studies that were used to create the COEB database. ${ }^{9}$ The 156 supplemental documents provided additional study details or data for the 51 included studies. Given the nature of the COEB project, the database and accompanying taxonomic meta-analysis are confined to studies including measures of BMI [e.g., weight $(\mathrm{kg}) /$ height $\left(\mathrm{m}^{2}\right)$, percentile, $\mathrm{z}$-score].

Two trained coders independently reviewed and extracted relevant study information, intended recipients, design and measurement, and intervention details from the 51 studies reporting on 58 separate interventions. The coder applied the relevant taxonomical code to each description, and in addition, coded elements of the study design and reported effects. ${ }^{9}$ These include a description of the study design, use (or not) of random assignment, number of participants, attrition, and timing of assessment(s), among others. These codes were applied to each reported effect so that each effect has its own set of codes. A standardized mean difference (Hedges' $g$ ) and its variance (or standard error) were coded whenever possible.
Given the application of a codebook, inter-rater reliability was assessed and is described in more detail in the Results article in this supplement. ${ }^{9}$

The database resulting from the comprehensive coding includes a table of contents, article log, the data set, and data set glossary, The taxonomies for components, outcomes, intended recipients, and intervention contexts are documented in the manual of procedures. The data set is arranged as an evidence map listing the relevant studies as rows, and selected outcomes, components, intended recipients, or intervention context as columns. Specifically, for the components, a " 1 " indicates the presence of a component as part of the intervention that produced the reported effect, and a " 0 " indicates that a component was not present; this was captured at the relevant social/ ecological model level. The COEB database is available for independent analysis, as a user may download it from online and integrate it into their preferred software (available online at https://www.nccor.org/childhoodobesity-evidence-base-test-of-a-novel-taxonomic-metaanalytic-method). Creating this open access to a searchable aggregated database has the potential to inform future initiatives, considering intended recipients, delivery 
Table 4. Childhood Obesity Evidence Base Project Intervention Context Components Identified across the 40 Reports Used for Taxonomy Development

\begin{tabular}{|c|c|c|c|c|c|c|}
\hline \multirow{2}{*}{$\begin{array}{l}\text { Intervention context } \\
\text { category }\end{array}$} & \multirow[b]{2}{*}{ Definition } & \multicolumn{5}{|c|}{ Socioecological model ${ }^{\mathrm{a}}$} \\
\hline & & Individual & Interpersonal & Organizational & Community & Societal \\
\hline Community type & Rural, suburban, urban & & & & $x$ & \\
\hline Geographic location & Region, state, city, country & & & & $x$ & \\
\hline Intervention setting & $\begin{array}{l}\text { Where intervention takes place; } \\
\text { within a school, child care center, } \\
\text { clinic, and so on }\end{array}$ & $x$ & $x$ & $x$ & $x$ & I \\
\hline $\begin{array}{l}\text { Instructor/facilitator } \\
\text { education and experience }\end{array}$ & $\begin{array}{l}\text { Includes number of years } \\
\text { providing instruction and } \\
\text { degrees/certifications }\end{array}$ & & $x$ & & & \\
\hline Instructor/facilitator gender & Gender of instructor(s) & & $x$ & & & \\
\hline Instructor/facilitator language & $\begin{array}{l}\text { Native language or language } \\
\text { proficiency of instructor(s) }\end{array}$ & & $x$ & & & \\
\hline $\begin{array}{l}\text { Instructor/facilitator race/ } \\
\text { ethnicity }\end{array}$ & Race/ethnicity of instructor(s) & & $x$ & & & \\
\hline School grade level & $\begin{array}{l}\text { The range of grade levels } \\
\text { accommodated at the school (i.e., } \\
\text { "K-5"; "high school"; "university") }\end{array}$ & $x$ & & $x$ & & \\
\hline $\begin{array}{l}\text { School/district/community } \\
\text { language status }\end{array}$ & $\begin{array}{l}\text { Description of language } \\
\text { proficiency at the school or } \\
\text { district level (i.e., student body } \\
\text { is mostly ELL) }\end{array}$ & & & $x$ & $x$ & \\
\hline $\begin{array}{l}\text { School/district/community } \\
\text { race/ethnicity composition }\end{array}$ & $\begin{array}{l}\text { Description of racial/ethnic } \\
\text { makeup of school or district }\end{array}$ & & & $x$ & $x$ & \\
\hline $\begin{array}{l}\text { School/district/community } \\
\text { socioeconomic status }\end{array}$ & $\begin{array}{l}\text { Description of school or district } \\
\text { SES, including "low income"; } \\
\text { "wealthy"; " } 50 \% \text { free or } \\
\text { reduced-price lunch" }\end{array}$ & & & $x$ & $x$ & \\
\hline $\begin{array}{l}\text { Caregiver/parent employ- } \\
\text { ment status }\end{array}$ & $\begin{array}{l}\text { Description of whether parents } \\
\text { are employed and to what extent }\end{array}$ & & $x$ & & & \\
\hline Caregiver/parent health status & $\begin{array}{l}\text { Characteristics of health status, } \\
\text { including BMI, obesity status, } \\
\text { pregnancy/breastfeeding, overall } \\
\text { health }\end{array}$ & & $x$ & & & \\
\hline $\begin{array}{l}\text { Caregiver/parent relationship } \\
\text { status }\end{array}$ & $\begin{array}{l}\text { Whether caregivers/parents } \\
\text { are single, divorced, separated, } \\
\text { married }\end{array}$ & & $x$ & & & \\
\hline $\begin{array}{l}\text { Caregiver/parent language } \\
\text { status }\end{array}$ & $\begin{array}{l}\text { Languages spoken by caregivers/ } \\
\text { parents }\end{array}$ & & $x$ & & & \\
\hline Caregiver/parent age & $\begin{array}{l}\text { Age ranges or absolute numbers } \\
\text { of years }\end{array}$ & & $x$ & & & \\
\hline Technology present in home & $\begin{array}{l}\text { Types of technologies available } \\
\text { include computers and phones }\end{array}$ & $x$ & $x$ & l & & \\
\hline
\end{tabular}

Frequencies are not provided here given the number of components, frequency of intervention context components in the final $5 \mathrm{I}$ studies can be found in the accompanying data set online.

${ }^{a}$ An $\mathrm{X}$ indicates that the socioecological model category was present within the initial 40 studies coded for taxonomy development, a / indicates where the research team, NCCOR Workgroup and External Expert Panel, anticipated finding articles in the expanded bibliography that describes the intervention component at that SEM level.

SES, socioeconomic status. 
channels, components, and contexts, thereby facilitating initiative customization and potentiating successful outcomes. While a user might imagine any number of possible analyses utilizing the COEB data set, a few expected uses include (1) comparing evidence from studies of varying levels of rigor and specificity, (2) examining the effectiveness of specific intervention components in the intended recipients and context, and/or (3) providing a comparison to evidence generated by well-accepted metaanalytic methods. Additional studies can also be added and coded using the same coding scheme. This will enable the COEB data set to grow and expand over time.

\section{Taxonomic Meta-Analytic Approach}

Meta-regression was used with the data set to examine the association between components and the overall effect sizes. Mixed-effects regression models in which the effect size estimates were used as the dependent and the components as the independent variables were estimated. Bivariate regression analyses were estimated to identify significant component categories or components. The details and final models of these analyses are described in the accompanying Results article. ${ }^{9}$

\section{Limitations}

Taxonomies, in our definition, are fluid and change in response to advances and evolutions in the field, as they are applied to new research. The COEB taxonomies are limited by the content of the 40 sources upon which they were built and 51 studies (and 147 supplemental materials) on which they were tested. We have mitigated these limitations through expert input from the NCCOR WG and EEP (see Acknowledgments). However, these taxonomies need to be tested with new research and refined as needed so that they keep pace with newly generated evidence. Given the scope of the COEB project to focus on studies with a weight outcome (usually BMI), interventions related to sleep, diet, and physical activity were included in the taxonomy development if they also reported on BMI. Thus, while the intervention components represent a variety of topic areas, they may not fully represent the breadth of childhood obesity interventions for the $2-5$ age group.

In addition, creating taxonomies and standardized language inherently requires subjectivity in classification. This is mitigated via input from the NCCOR WG and EEP that offered a range of perspectives on how the field conceptualizes various components of the taxonomies. We also generated definitions for each taxonomic element so the taxonomy can be used and understood by others. And finally, limitations of the taxonomic meta-analysis are discussed in the accompanying Rationale article. ${ }^{4}$

\section{Conclusion}

The taxonomies described here provide a "common language" for researchers, practitioners, policymakers, and other stakeholders to communicate about childhood obesity prevention interventions. This effort supports others in the field of implementation science by establishing a common language for describing the components of interventions and the context around them, which is essential for translating research to practice, and understanding the extent to which intervention components are being implemented as intended. ${ }^{18,19}$ This work represents another step toward building the evidence needed to accelerate the reduction in childhood obesity. This later objective is a primary mission of NCCOR, which supported this effort to advance innovative methodologies in the obesity prevention field.

\section{Acknowledgments}

This work is a collaborative effort between Mission Measurement and the National Collaborative on Childhood Obesity Research (NCCOR). It was funded by Office of Behavioral and Social Science Research, National Institutes of Health, and guided by members of NCCOR. The four organizations represented in NCCOR are: The Centers for Disease Control and Prevention (CDC); National Institutes of Health (NIH); Robert Wood Johnson Foundation (RWJF); and the United States Department of Agriculture (USDA). Members of the NCCOR Childhood Obesity Evidence Base (COEB) project Working Group include Sonia Arteaga, Christine Hunter, Young Jo, Laura Kettel Khan, and Deborah Young-Hyman. Members of the COEB External Expert Panel (EEP) include Leann Birch, John Cawley, Jamie Chriqui, Angie Cradock, Christina Economos, Debra Haire-Joshu, Shiriki Kumanyika, Bruce Lee, Lorrene Ritchie, Thomas Robinson, and Marlene Schwartz. We are grateful to the Systematic Review and Meta-Analysis Research Methods Team, especially Melissa M. Feulner, Brittany L. Balletto, and Julie DeCosta for their efforts on this project. This Childhood Obesity Supplement is dedicated to Dr. Leann L. Birch, who passed May 26, 2019 , for a life's work devoted to childhood nutrition and health.

\section{Funding Information}

The research reported in this article was supported by the Office of Behavioral and Social Science Research of the National Institutes of Health (NIH) under contract number GS-00F-0007M. The findings and conclusions in this report are those of the authors and do not necessarily represent the official position of the NIH or the Centers for Disease Control and Prevention (CDC).

\section{Author Disclosure Statement}

No competing financial interests exist. 


\section{References}

1. Centers for Disease Control. Overweight \& Obesity. 2019. Available at https://www.cdc.gov/obesity/index.html Last accessed November 21, 2019.

2. Rodgers GP, Dietz W, Lavizzo-Mourey R. Research on childhood obesity: Building the foundation for a healthier future. Am J Prev Med 2018;54:450-452.

3. Brown CL, Halvorson EE, Cohen GM, et al. Addressing childhood obesity: Opportunities for prevention. Pediatr Clin North Am 2015;62:1241-1261.

4. Hedges LV, Saul JA, Cyr C, et al. Childhood Obesity Evidence Base Project: A rationale for taxonomic versus conventional metaanalysis. Childhood Obes 2020;16:S2-1-S2-6.

5. Colquhoun H, Leeman J, Michie S, et al. Towards a common terminology: A simplified framework of interventions to promote and integrate evidence into health practices, systems, and policies. Implement Sci 2014:9:154.

6. Michie S, Van Stralen MM, West R. The behaviour change wheel: A new method for characterizing and designing behaviour change interventions. Implement Sci 2011;6:42.

7. Century J, Cassata A. Implementation Research: Finding common ground on what, how, why, where, and who. Rev Res Educ 2016; 40:169-215.

8. Proctor EK, Powell BJ, McMillen JC. Implementation strategies: Recommendations for specifying and reporting. Implement Sci 2013;8:139.

9. Scott-Sheldon LAJ, Hedges LV, Cyr C, et al. Childhood Obesity Evidence Base Project: A systematic review and meta-analysis of a new taxonomy of intervention components to improve weight status in children 2-5 years of age, 2005-2019. Childhood Obes 2020;16:S2-21-S2-48.

10. McLeroy K, Bibeau D, Streckler A, et al. An ecological perspective on health promotion programs. Health Educ Q 1988;15:351-377.
11. Jernigan J, Dawkins-Lyn N, Dooyema C, et al. Childhood obesity declines project: highlights of community strategies and policies. Child Obes 2018;14(Suppl 1):S32-S39.

12. Century J, Rudnick M, Freeman C. A framework for measuring fidelity of implementation: A foundation for shared language and accumulation of knowledge. Am J Eval 2010;31:199-218.

13. Hall GE, Hord SM. Change in Schools: Facilitating the Process. SUNY Press, State University of New York-Albany: Albany, NY, 1987.

14. Riley WT, Rivera DE. Methodologies for optimizing behavioral interventions: Introduction to special section. Trans Behav Med 2014;4:234-237.

15. Glaser B, Strauss A. The Discovery of Grounded Theory: Strategies for Qualitative Research. Aldine: Chicago, 1967.

16. Strauss A, Corbin J. Grounded theory methodology. Handb Qual Res 1994; 17:273-85.

17. Tran V-T, Porcher R, Falissard B, et al. Point of data saturation was assessed using resampling methods in a survey with openended questions. J Clin Epidemiol 2016;80:88-96.

18. Eccles MP, Armstrong D, Baker R, et al. An implementation research agenda. Implement Sci 2009;7:4-18.

19. Rapport F, Clay-Williams R, Churruca K, et al. The struggle of translating science into action: Foundational concepts of implementation science. J Eval Clin Pract 2018;24:117-126.

Address correspondence to:

Heather King, PhD

Impact Genome Project, Mission Measurement 200 North LaSalle Street

Suite 2650

Chicago, IL 60601

USA

E-mail: hking@missionmeasurement.com 